IFN Working Paper No. 832, 2010

\title{
Subsidizing Away Exports? A Note on R\&D- policy towards Multinational Firms
}

Pehr-Johan Norbäck 


\title{
Subsidizing away exports?
}

\section{A note on R\&D-policy towards multinational firms*}

\author{
Pehr-Johan Norbäck \\ Research Institute of Industrial Economics
}

May 18, 2010

\begin{abstract}
In this paper, I investigate whether instead of strengthening home-based production, government R\&D-subsidies can induce R\&D-intensive firms to locate production abroad. Investigating firm-level data on Swedish MNEs, however, I find no evidence of such relocation. R\&D subsidies rather tend to encourage export production at the expense of foreign production. The theory presented suggests that this is consistent with technology transfer costs, which outweigh trade costs for physical goods.

Keywords: Multinational Firms, R\&D, Subsidies, Location, Empirical Analyses JEL classification: L13, F23, O33
\end{abstract}

*I want to thank Susana Aparicio for helpful data assistance and Statistics Sweden for providing additional data. Financial support from the Marianne and Marcus Wallenberg Foundation and the Jan Wallander and Tom Hedelius Foundation is gratefully acknowledged. 


\section{Introduction}

On December 11, 2008, the Swedish government announced that it would launch a rescue plan for the Swedish vehicle industry. The government would potentially invest SEK 28 Billion (USD 8 Billion) in an attempt to save car producers VOLVO and SAAB, as well as numerous sub-contractors, from vanishing in the storm generated by the global financial crisis . This rescue package was to ensure that firms could obtain financing to develop more environment-friendly technologies. The government also launched a new research institute in order to "strengthen the competitiveness of the Swedish vehicle industry", with the aim of keeping Sweden's position as one of the few countries in Europe capable of hosting the full chain of vehicle production from research and design to production (Dagens Nyheter, December 12, 2008).

While the present financial distress has put government support to the business sector at the forefront, government industrial support has been a major issue in international policy discussions for a long time. ${ }^{1}$ A substantial share of this government support is directed towards Research and Development (R\&D) and, in some countries, government support to R\&D may constitute up to $1 / 3$ of business R\&D. In general, two motives seem relevant for explaining such huge government investments: First, R\&D is seen as important in generating and sustaining economic growth; that is, in addition to the internal benefits for an inventing firm, $R \& D$ or $R \& D$-intensive production also has external benefits since the knowledge created is not fully appropriable. Due to such knowledge spillovers, R\&D tends to be under-provided from a social perspective. Many countries also use subsidies to appropriate rents on international markets to domestic firms, so-called strategic trade- or industrial policy (see, for instance, Brander, 1995). ${ }^{2}$

What is not always recognized is that the benefits of subsidy polices often accrue to Multinational Enterprises (MNEs). ${ }^{3}$ Granting R\&D subsidies to MNEs does not necessarily

\footnotetext{
${ }^{1}$ According to OECD, annual programs transfer some US $\$ 50$ billion from public budgets to the enterprise sector. "Public Support to Industrial R\&D Efforts", available at http://www1.oecd.org/dsti/ sti/prod/intro-21.htm. OECD (1996).

${ }^{2}$ Recent papers investigating the effect of subsidy policies in international oligopolistic markets are Haaland and Kind (2008) and Neary and Leahy (2009).

${ }^{3}$ The car producers VOLVO and SAAB are owned by the US firms FORD and GM with global car
} 
mean that R\&D-intensive production increases in the home country, since an MNE may transfer new technologies or products into overseas production. ${ }^{4} 5$

The purpose of this paper is to investigate the impact of $R \& D$ subsidies on a firm's location decision. To this end, I extend Norbäck (2001), which examines how (endogenous) $\mathrm{R} \& \mathrm{D}$ affects a firm's location choice, to incorporate the effect of R\&D subsidies on the location of production. I investigate the following scenario: The government first states a per unit R\&D subsidy. Then, given that subsidy, a monopoly firm makes three distinct choices: It invests in costly R\&D to improve its technology, thereby decreasing its marginal cost. Then, it either implements the technology in an affiliate supplying a foreign market from a local plant, or in a domestic plant supplying the foreign market by export production. Given the location choice, the firm chooses how much to sell.

The fact that export production is subject to a trade cost is taken into account by the firm, but also the fact that implementing the technology abroad is more costly, due to technology transfer costs. ${ }^{6}$ Since foreign direct investment (FDI) avoids the trade cost, larger sales in foreign production also allow for increased spending on $R \& D$, as compared to the alternative of exports. This trade cost-effect tends to make affiliate production more profitable and, consequently, a location of production abroad becomes more likely. However, overseas production implies that technology needs to be transferred from home producing capabilities. In the empirical analysis conducted below (1965-1998), VOLVO and SAAB were Swedish-owned firms.

${ }^{4}$ Indeed, MNEs often dominate R\&D activities in their home countries. For example, in 1965, ten MNEs accounted for $75 \%$ of the business R\&D expenditures in Sweden. In 1994, this share had risen to $90 \%$ (Jakobsson (1999)). In 2004, 22 Swedish and 12 foreign multinationals accounted for $70 \%$ of all aggregate R\&D expenditures in Sweden (ITPS, 2007). Indeed, the ability to add the services of their firm-specific assets into additional production facilities at low costs is often put forward as a key ingredient in explaining the existence of MNEs (see Dunning (1977) and Markusen (1995)).

${ }^{5}$ In this vein, Blomström (2000) argues that Sweden as a country lost market shares in international markets when large Swedish MNEs increased their share of world markets. At the same time, generous government subsidies to R\&D were granted. Technology policies may then have increased an on-going process leading MNEs to utilize assets abroad instead of domestically. While subsidy policies may have served to increase the rents of Swedish firms, the externalities associated with high-tech production in Sweden may not have materialized.

${ }^{6}$ Teece (1977) provides strong evidence of the existence of such technology transfer costs. 
R\&D labs. Costly transfers of technology then tend to restrict the firm's R\&D, a transfer cost-effect which tends to make export production more profitable.

The model predicts that when transfer costs are small, high-tech firms will choose FDI, and that subsidies to R\&D reinforce the incentives to migrate production. At higher transfer costs, on the other hand, high-tech firms choose to export. In the latter case, R\&D-subsidies reinforce the alternative of home-based export production.

Using firm-level regressions on a data set of Swedish multinational firms, I first find a statistically significant negative correlation between R\&D intensity and my location measure, the affiliate share of foreign sales. This is surprising considering the close tie in the literature between firm-specific assets and MNEs, but it confirms earlier findings in Norbäck (2001), where exports were shown to be the preferred choice by R\&D-intensive firms. From the theoretical model, $R \& D$ subsidies should then also give rise to export production, since the negative correlation between R\&D intensity and the affiliate share of foreign sales suggests that the transfer cost-effect dominates the trade cost-effect. Indeed, I find no evidence of R\&D-subsidies contributing to relocating production abroad. In contrast, consistent with my theoretical model, there is evidence that, at the margin, R\&D-subsidies induce firms to choose home-based export production.

It should be noted that the presented theory based on a monopoly firm easily extends into MNE oligopoly models. Some related papers investigating policy in the presence of MNEs are Horstmann and Markusen (1992) and Smith (1987) examining tariffs, Flam (1994) studying voluntary export restraints, and Dick (1993) investigating the consequences of foreign ownership. Sanna-Randaccio (2002) shares some similarities with the present paper. In contrast to the previous literature, she also allows for both $R \& D$ and location to be endogenously determined. However, while her paper theoretically investigates the welfare effects of lump-sum subsidies from a home government trying to attract inward FDI, this paper investigates outward FDI. In particular, its contribution is to both theoretically and empirically investigate the effects of government R\&D policy (in terms of per unit of R\&D subsidies) on a firm's R\&D and location choice. Thereby, it stresses the impact of technology transfer costs, which are not considered in Sanna-Randaccio (2002). The paper is organized as follows. In section 2 , the theory is presented. In section 3 , I test the 
implications of the theory and section 4 concludes the paper.

\section{Theory}

In this section, I will investigate how R\&D subsidies issued by the government affect a firm's choice between foreign and export production, as alternative means of serving a market abroad.

Table 1: Key assumptions in the theoretical model.

\begin{tabular}{|c|c|c|}
\hline & Expression: & Numbering: \\
\hline Demand: & $P_{h}=a-\frac{q_{h}}{s}$ & (1) \\
\hline Profit: & $\Pi_{h}=\left(P_{h}-c_{h}\right) q_{h}-\mathcal{F}_{h}+\sigma x_{h}$ & $(2)$ \\
\hline \multirow[t]{2}{*}{ Marginal costs: } & $c_{h}=C_{h}-\theta x_{h}$, & $(3)$ \\
\hline & $C_{h}= \begin{cases}c_{0}, & h=A \\
c_{0}+t & h=E\end{cases}$ & (4) \\
\hline Fixed costs: & $\mathcal{F}_{h}=F_{h}+T_{h}+G_{h}$ & $(5)$ \\
\hline$-\mathrm{R} \& \mathrm{D}$ & $F_{h}=\gamma \frac{\left(x_{h}\right)^{2}}{2}$ & (6) \\
\hline - Transfer & $T_{h}= \begin{cases}\gamma \frac{\delta(2+\delta)}{2}\left(x_{h}\right)^{2} \geq 0, & h=A \\
0, & h=E\end{cases}$ & $(7)$ \\
\hline - Plant & $G_{h}= \begin{cases}G, & h=A \\
0, & h=E\end{cases}$ & (8) \\
\hline
\end{tabular}




\subsection{The model}

The model presented builds on Norbäck (2001). There is a single firm producing a homogeneous good. The demand is located in another country, which may be considered as the world market for the good in question. The government first states a per unit of R\&D subsidy and then, the firm makes three decisions: It invests in costly R\&D at home. I assume the technological level of the firm to be represented by its cost level of production, and that $\mathrm{R} \& \mathrm{D}$ reduces the marginal cost. Then, the technology is implemented either in export production from a home factory (henceforth denoted $E$ ), or there is a direct investment (henceforth denoted FDI) and production takes place in a foreign affiliate (henceforth denoted $A$ ). Finally, the market is supplied. It is assumed that the government cannot condition its subsidy on the location choice of the firm. ${ }^{7}$

Subscripts will denote location. For example, $q_{h}$ is the output choice of the firm in location $h$, for $h=\{E, A\}$. Hence, $q_{E}$ is the export quantity of the firm, whereas $q_{A}$ is the production quantity when an affiliate is established.

Demand is linear and given by (1) in Table 1, where $a>0$ is a demand parameter and $s>0$ can be interpreted as a measure of the size of the market. Total profit $\Pi_{h}$ is expressed as (2). Note that $\left(P_{h}-c_{h}\right) q_{h}$ is variable profits, where the marginal cost $c_{h}$ is given in (3) and (4), where $\theta$ and $c_{0}$ are positive constants. Several factors affect the marginal cost. The firm chooses a level of R\&D, indicated by $x_{h}$, which reduces its marginal cost. Export production is also subject to a trade cost (transport cost or tariff barrier), $t$, which can be avoided by FDI.

Turning to fixed costs $\mathcal{F}_{h}$ in (2), as shown in (5), these come as three types: $F_{h}, T_{h}$ and $G_{h}$ :

First, R\&D is assumed to incur quadratic costs, so that in $(6), x_{h}$ gives rise to firmspecific fixed costs of $F_{h}=\frac{\gamma\left(x_{h}\right)^{2}}{2}$, where $\gamma$ is a positive constant.$^{8}$

\footnotetext{
${ }^{7}$ When government agencies support the development of a product, financing is provided at the development stage often years before actual production takes place. The government could, in principle, write a contract conditioning payments in the development phase on the location production. Such practice seems rare, however. Conditions for the location of production appear not to be attached to government support in Sweden.

${ }^{8}$ See Cheng (1984).
} 
Second, technology transfer costs are given in (7). Following Teece (1977), transfer costs for implementing the technology in a factory located abroad are assumed to be higher. I normalize such that new technology can be implemented at home without cost, whereas there is an additional cost $T$ of transferring the technology abroad, since it must be adapted to local conditions. ${ }^{9}$ I then define a parameter $\delta$ such that $0 \leq \delta_{A}<\infty$, for foreign production and $\delta_{E}=0$ for export production. This implies that a given level of R\&D, $x$, equally reduces the cost of production, irrespective of location (cf. equation (3)), but that the implementation of the technology abroad requires additional R\&D efforts amounting to $\delta x$. Total R\&D costs are then $\frac{\gamma\left((1+\delta) x_{A}\right)^{2}}{2}$, which can be separated into research costs $F_{A}=\gamma \frac{\left(x_{A}\right)^{2}}{2}$ and transfer costs $T_{A}=\gamma \frac{\delta(2+\delta)}{2}\left(x_{A}\right)^{2}$. Note that $T(\cdot)$ is increasing with the level of $\mathrm{R} \& \mathrm{D}, x$. This reflects the fact that more complex technologies may require a closer interchange of information with manufacturing, thereby increasing communication and information costs if production is located abroad. ${ }^{10}$

Third, the firm has production units at home, but initiating production abroad involves additional plant-level investments. Plant-level fixed costs $G_{h}$ are then defined in (7).

Finally, the last term in (2) $\sigma x_{h}$ shows the total subsidy payments where $\sigma$ is a per unit of R\&D subsidy. The effect of this term on the firms location decision constitutes the key interest in the analysis.

Profit-maximizing production quantities, $q_{h}$, and R\&D expenditures, $x_{h}$, are chosen so that (9) must hold:

$$
\frac{\partial \Pi_{h}}{\partial q_{h}}=P_{h}-c_{h}-\frac{q_{h}}{s}=0, \quad \frac{\partial \Pi_{h}}{\partial x_{h}}=\theta q_{h}+\sigma-\left(1+\delta_{h}\right)^{2} \gamma x_{h}=0
$$

As shown by Leahy and Neary (1996), all endogenous variables can be solved in a parameter $\eta$, defined as:

$$
\eta \equiv \frac{\theta^{2} s}{\gamma} \geq 0
$$

\footnotetext{
${ }^{9}$ I model the costs of transferring the new technology to a foreign affiliate in a very simple way. Markusen (2002) uses a more general model to show how firms with knowledge-capital intensive production risk asset dissipating when producing abroad and how this affects the choice between foreign production and exporting. Agency problems affecting the mode to serve a foreign market are also extensively discussed in Barba-Navaretti and Venables (2004).

${ }^{10}$ The assumption of a quadratic transfer cost is not essential. What is important is that the transfer cost influences the level of R\&D, $x$.
} 
Table 2: Profit as function of location choice.

Reduced-form profits, sales and R\&D

$$
\begin{gathered}
\hline \text { Export production } \begin{aligned}
\Pi_{E}(\eta) & =\frac{1}{2 s}\left(q_{E}\right)^{2}(2-\eta)+\frac{\sigma^{2}}{2 \gamma} \\
q_{E} & =\frac{s(\mathcal{A}-t)+\sigma \frac{\eta}{\theta}}{2-\eta} \\
x_{A} & =\left(\frac{\theta}{\gamma} q_{E}+\frac{\sigma}{\gamma}\right) \\
\text { Affiliate production } & \\
\Pi_{A}(\eta) & =\frac{1}{2 s}\left(q_{A}\right)^{2}\left(2-\frac{\eta}{\tau}\right)-G+\frac{\sigma^{2}}{2 \gamma \tau} \\
q_{A} & =\frac{s \mathcal{A}+\sigma \frac{\eta}{\tau \theta}}{2-\frac{\eta}{\tau}} \\
x_{A} & =\frac{1}{\tau}\left(\frac{\theta}{\gamma} q_{A}+\frac{\sigma}{\gamma}\right)
\end{aligned}
\end{gathered}
$$

which may then be interpreted as the relative return to R\&D. Note that $\eta$ is zero, if $R \& D$ is completely ineffective $(\theta=0)$, infinitely costly $(\gamma=\infty)$ or if the size of the market is very small $(s=0)$.

For well-behaved solutions, I make two assumptions on parameter values: (i) The firm always have a strict positive marginal cost which, by (3), implies that $c_{h}>\theta x_{h}$ holds. (ii) Profits are always positive in both locations. This, in turn, implies that $\frac{\eta}{\tau}<2$ must hold, where parameter $\tau$ is a measure of the impact of the transfer cost: ${ }^{11}$

$$
\tau \equiv(1+\delta)^{2} \geq 1
$$

Using (9)-(11), I can derive reduced-form functions for the profit level $\Pi_{h}(\eta)$, production level $q_{h}(\eta)$ and R\&D level $x_{h}(\eta)$ for each location choice $h$ in $\eta$. These are given in Table 2 , where it will be assumed that $\mathcal{A}-t>0$ and $\mathcal{A}=a-c_{0}>0 .{ }^{12}$

\footnotetext{
${ }^{11}$ In the appendix, it is shown that the latter assumption guarantees that the second-order condition for the firm's maximization is fulfilled.

${ }^{12}$ These conditions are necessary to guarantee that production is profitable.
} 


\subsection{The equilibrium location and the effect of R\&D-subsidies}

I can now address the question of whether subsidies to R\&D can generate a relocation of production to abroad. For this purpose, I proceed as follows:

I first characterize the type of firm choosing FDI/exports, which can conveniently be done in terms of the relative return to $\& \& D, \eta$. This is also useful for the empirical exercise in the next section, as $\eta$ can be shown to be positively related with a firm's R\&D-intensity, defined as the share of R\&D-expenditures of its sales. Then, I investigate the effect of a subsidy to $\mathrm{R} \& \mathrm{D}$ on a marginal firm's location decision. I summarize the results and additional comparative statics results in Table 3. It is easy to show the following Lemma:

Lemma 1 The reduced-form profit function $\Pi_{h}(\eta)$ is increasing or non-decreasing in the relative return to $R \mathscr{E} D, \eta$.

Proof. See the appendix.

The profit in export and foreign production increases in $\eta$ simply because a higher return to $R \& D$ implies higher spending on $R \& D$, thereby lowering the marginal costs. I can now describe the location decision:

Lemma 2 Suppose the parameter values to be such that reduced-form total profits are equal in export- and affiliate production at some $\eta^{*}$, that is, $\Pi_{E}\left(\eta^{*}\right) \equiv \Pi_{A}\left(\eta^{*}\right)$. Then, if technology transfer costs are low $\tau<\tau^{*}$, a firm endowed with a high relative return to $\operatorname{RED}, \eta>\eta^{*}$, chooses FDI, whereas a firm endowed with a low return to R\&D $\eta<\eta^{*}$ exports. The opposite holds if technology transfer costs are high, $\tau>\tau^{*}$.

Proof. See the appendix.

This result is due to the relative strength of two opposing forces.

Since FDI avoids the transport cost, larger sales in foreign production also imply increased spending on R\&D, as compared to the alternative of exports. This follows directly from (9), where the marginal revenue of research is $\theta q_{h}+\sigma$. In turn, more R\&D leads to lower marginal cost and additional sales, further increasing R\&D-expenditures. Affiliate production therefore tends to result in a more efficient production technology, generating 
a difference in marginal costs between the two location alternatives which tends to exceed the transport cost, $t .{ }^{13}$ This trade cost-effect tends to make profits in affiliate production more responsive to a increase in the relative return to $\mathrm{R} \& \mathrm{D}, \eta$, and works towards high-tech (R\&D intensive) firms choosing FDI.

However, locating production abroad implies that technology must be transferred from home $\mathrm{R} \& \mathrm{D}$ labs. At an increasing relative return to $\mathrm{R} \& \mathrm{D} \eta$, increasing technology transfer costs tend to restrict the firm's R\&D which, in turn, limits the reduction of the marginal cost in production, if affiliate production is chosen. Once more, this can be seen from (9) where the marginal cost of $\mathrm{R} \& \mathrm{D}$ with production abroad is $\tau \gamma x_{A}$, which can be compared to the marginal cost of $\mathrm{R} \& \mathrm{D}$ when exports is chosen, $\gamma x_{E}$. This transfer cost-effect then tends to make profits in export production more responsive to an increase in the relative return to $\mathrm{R} \& \mathrm{D}, \eta$, and influences high-tech firms to choose exporting.

For low transfer costs, $\tau<\tau^{*}$, high-tech firms with $\eta>\eta^{*}$, produce abroad. Intuitively, these firms then gain more by avoiding transfer costs than by avoiding trade costs associated with physical goods. For low transfer costs, the roles are changed and high-tech firms produce abroad.

The effects of R\&D-subsidies can now be described as follows:

Proposition 3 Suppose that parameter values are such that total profits are equal in export- and affiliate production at some $\eta^{*}$. If technology transfer costs are low, $\tau<\tau^{*}$, a government subsidy to $R \mathscr{E} D, \sigma$, induces the marginal firm endowed with a relative return to RED $\eta^{*}$ to choose FDI, whereas this firm will export if technology transfer costs are high, $\tau>\tau^{*}$.

Proof. See the Appendix.

The proposition can be understood as follows: At low transfer costs, the trade-cost effect (where expanding sales and increasing R\&D-expenditures reinforce each other), dominates the transfer-cost effect (where higher transfer costs limit the resources spent R\&D). In this case, an R\&D-subsidy further strenghtens the trade cost-effect, and induces the marginal firm to produce abroad. On the other hand, at high transfer costs, an R\&D subsidy

\footnotetext{
${ }^{13}$ Comparing marginal costs, note that $\Delta c=c_{E}-c_{A}$, which can be written as $\Delta c=t+\theta\left(x_{A}-x_{E}\right)$.
} 
induces the marginal firm to export and the transfer-cost effect dominates the trade-cost effect. Intuitively, as research and production are geographically separated when affiliated production is chosen, an R\&D-subsidy then gives rise to smaller cost-savings, as research takes place at a high marginal cost.

Table 3 summarizes Lemma 2 and Proposition 3 and adds additional comparative statics results. ${ }^{14}$ In each case of low- and high technology transfer costs, the first column indicates an increase in the exogenous variable, $z$. The second column shows the qualitative effect on a firm endowed with a relative return $\eta^{*}$ which, ex-ante, is indifferent between exporting or producing abroad. The third column translates this into the "marginal effect" on this firm's incentive to choose FDI and locate production abroad. ${ }^{15}$ We can then note that whatever the size of transfer costs, the marginal firm chooses FDI when plant-level fixed costs $G$ and trade costs $t$ are higher, whereas this firm chooses exports when there is an increase in transfer costs $\tau$.

\section{Empirical analysis}

In this section, I will investigate how R\&D-subsidies have affected the location decisions of Swedish multinational firms. I first show how a test can be performed based on the theory presented in the last section. Then, I describe data and the included variables.

\subsection{The econometric model}

The theory predicts a firm's choice between implementing its technology in export or affiliate production. Translating this prediction into an empirical analysis, I follow Brainard (1997) and use the share of foreign sales accounted for by the affiliates as my dependent variable. This variable is labeled $A F S H A R E_{i t}$, and is defined as:

$$
A F S H A R E_{i t}=\frac{S Q_{i t}}{S Q_{i t}+S X_{i t}}
$$

\footnotetext{
${ }^{14}$ Table 3 assumes a small subsidy. The appendix presents simulations which show that these results also extend to subsidies that are not infinitesimal.

${ }^{15} \mathrm{~A}$ decrease in $\eta^{*}$ is indicated by a minus sign, an increase in $\eta^{*}$ by a plus sign.
} 
Table 3: Comparative statics results

\begin{tabular}{lcc}
\hline Panel $(\mathrm{i})$ & \multicolumn{2}{c}{ Low transfer costs, $\tau<\tau^{*}$ and FDI when $\eta>\eta^{*}$} \\
\cline { 2 - 3 } Variable: & Effect on $\eta^{*}$ & Marginal effect on the FDI decision: \\
\hline \hline$\sigma$ & $(-)$ & + \\
$\tau$ & $(+)$ & - \\
$G$ & $(+)$ & + \\
$t$ & $(-)$ & - \\
\hline Panel (ii) & High transfer costs, $\tau>\tau^{*}$ and FDI when $\eta<\eta^{*}$ \\
\cline { 2 - 3 } Variable: & Effect on $\eta^{*}$ & Marginal effect on the FDI decision: \\
\hline \hline$\sigma$ & $(-)$ & \\
$\tau$ & $(-)$ & - \\
$G$ & $(-)$ & + \\
$t$ & $(+)$ & \\
\hline
\end{tabular}

where $S Q_{i t}$ denotes the level of foreign production for firm $i$ at time $t$ and $S X_{i t}$ is the corresponding export level. This relative measure then indirectly captures the implementation choices of the firms, since the sales pattern must reflect location choices. It also subsumes the two endogenous variables, export and affiliate production, into a single variable.

The following equation is estimated:

$$
\begin{aligned}
\text { AFSHARE }_{i t}= & \alpha_{0}+\alpha_{1} \text { RDINT }_{i t}+\alpha_{1} R D S U B_{h t}+\alpha_{3} T R A N S P_{h t} \\
& +\alpha_{4} G S C A L E_{h t}+\alpha_{5} A G E_{i t}+\varepsilon_{i t} .
\end{aligned}
$$

The variables are presented in more detail below.

\subsubsection{Dependent variable}

To calculate the dependent variable, $A F S H A R E_{i t}$, I use data on outward FDI by Swedish MNEs, originating from the Research Institute of Industrial Economics (RIIE). I use data 
from seven surveys: 1965, 1970, 1974, 1978, 1986, 1990 and 1994. The surveys cover firms which have at least one production affiliate abroad. They include almost all Swedish multinational firms in the manufacturing sector, and detailed information is available on variables such as $\mathrm{R} \& \mathrm{D}$, employment, production and their distribution between domestic and foreign units, as well as internal and external trade flows.

The analysis takes place on the firm level, i.e. the overall foreign activity of firm $i$ is examined. Hence, aggregating over all countries $j$ in which firm $i$ records sales, exports and affiliate sales are calculated as $S X_{i t}=\sum_{j} S X_{i j t}$ and $S Q_{i t}=\sum_{j} S Q_{i j t}$. I choose to focus on OECD countries, since the modelling framework does not emphasize differences in factor costs. ${ }^{16}$ In addition, sales to OECD countries cover the vast majority of foreign sales for the firms in the sample. When calculating $S X_{i t}$, I use exports sales of final goods only; so exports of input goods to the affiliates are excluded. I also exclude exports back to Sweden by affiliates from $S Q_{i t}$. These measures are due to the absence of input-goods and home-market effects in the theoretical section.

\subsubsection{Exogenous variables}

In table 4, the independent variables and the corresponding exogenous variables from the theoretical section (for which they act as proxies), are presented. For convenience, I also reproduce their expected sign (absent the $R \& D$ variables), based on my findings in the theoretical section.

I will use the contemporaneous R\&D intensity, $R D I N T_{i t}$, defined as the share of $\mathrm{R} \& \mathrm{D}$ expenditures in the total sales of the firm in time $t$, as a proxy for the relative return to $R \mathscr{G}, \eta \cdot{ }^{17}$

Since R\&D expenditures are endogenously determined in the theoretical section, there may be an endogeniety problem with the $R \& D$ variable in the empirical analysis. The theory presented suggests that a lagged $R \& D$ intensity may be considered (since $R \& D$

\footnotetext{
${ }^{16}$ The countries included are: Belgium, France, Italy, the Netherlands, Germany, Luxemburg, UK, Norway, Ireland, Denmark, Spain, Portugal, Greece, Finland, Austria, Switzerland, USA, Canada, Japan, Australia and New Zealand. The last two countries are combined into one single country observation.

${ }^{17}$ Using Table 2 and assuming a small subsidy, RDINT can be written as $\frac{x_{h}}{P * q_{h}}=\frac{\theta}{\gamma} \frac{1}{P}$. From Table 2 and (1), it also follows that $\frac{d P}{d q_{h}} \frac{d q_{h}}{d \eta}<0$. Hence, RDINT must be monotonously increasing in $\eta$.
} 
expenditures are set before the location decision and the sales decision). Ravenscraft and Scherer (1982) propose a lag of approximately five years between $R \& D$ expenditures and profits, which suggests that the four-year lag, corresponding the one period lag in terms of surveys, should be treated as endogenous. To reduce any simultaneity bias, one alternative is then to use the eight year lag on R\&D intensity. I will, however, only report a specification using the contemporaneous $\mathrm{R} \& \mathrm{D}$ intensity $R D I N T_{i t}$ as an instrument for the four-year lag. As discussed in Norbäck (2001), this prevents a massive loss of observations associated with the eight-year lag, due to a heavily unbalanced firm panel, as many firms disappear when they are acquired or reorganized over time. Note that given that $R \& D$ is conducted before sales take place, $\mathrm{R} \& \mathrm{D}$ in time $t$ should also be uncorrelated with the error term in (16). The latter also points to the advantage of using specifications with the contemporaneous R\&D intensity, $R D I N T_{i t}$, as a proxy for $\eta$ since this avoids the loss of observations and the potential selection bias associated with a lagged R\&D intensity.

For R\&D subsidies, I do not have data on subsidies individual firms have received. Instead, government subsidies to $\mathrm{R} \& \mathrm{D}, \sigma$, are measured as the share of total $\mathrm{R} \& \mathrm{D}$ expenditures at the Swedish two-digit industry level financed by the government. Here, I use data from the OECD - Basic Science and Technology Statistics (1999) and SCB (1965, 1970). Since I am investigating the effects of government subsidies on the location of production, $R D S U B_{h t}$ is the key variable in the analysis.

To measure the plant level fixed costs G, I use a measure of plant size calculated from Swedish industrial statistics. GSCALE $E_{h t}$ is then defined as the average size of plants in terms of the number of employees for plants with more than one hundred employees, in the three- or four-digit industry $h$ to which the firm belongs.

As a measure of trade costs, $t$, I use $T R A N S P_{h t}$ which is the share of transport costs in total variable costs, and once more, Swedish three- or four-digit industry level data are used. In addition to transport costs, total variable costs include costs for electricity, raw materials and packing as well as wages for blue-collar workers.

Finding a variable capturing the effect of technology transfer costs is problematic. Swedenborg (1982) argues that more experience of production abroad should reduce technology transfer costs to units abroad. To capture the effects of experience in foreign production, I 
use the variable $A G E_{i t}$, which is a weighted average of the mean age of the affiliates in the respective countries in which the firm is active. Weights are calculated as the share of the world-wide number of affiliates the firm holds in a host country. ${ }^{18} \mathrm{I}$ do not include a market size measure since the overall world-wide foreign activity of firm $i$ is examined which makes it difficult to measure demand. The growth in the world market might be captured by the time fixed effects which are included in all specifications. ${ }^{19}$ Additional fixed effects are also included (see below). Summary statistics for all variables are provided in Table 5.

\subsection{Estimation results}

Table 6 reports the results from estimating (16). Specification (i) controls for time-specific and industry-specific effects. In specification (ii), I undertake panel estimations controlling for firm-specific and time-specific effects, since unobservable firm-characteristics may drive the results. In specification (iii), I use a tobit specification since the dependent variable AFSHARE is bounded between zero and one. Finally in (iv), a 2SLS estimation is performed where the contemporaneous R\&D-intensity is used as an instrument for the four year lag in R\&D-intensity. Specifications (i), (iii) and (iv) include time-specific and two-digit industry-specific effects.

Irrespective of the specification, the estimated coefficient for RDINT is negative and highly significant; that is, the larger the R\&D intensity, the smaller is the share of foreign

\footnotetext{
${ }^{18}$ Ideally, one would like to find a direct measure of technology transfer costs. A measure using the age of the affiliates should reflect that such costs are lower in more experinced firms but, admittedly, this is not an exact measure. It is very hard to find alternatives, however. One alternative, which has been suggested, is to try measures of royalty payments from the affiliates back to the parents as a proxy for technology transfer costs. However, there are reasons to believe this to be a biased measure. First, it is not clear how royalties would reflect the cost of transferring technology. As a part of the firm's internal pricing system, they could equally well just reflect profit flows from the affiliates. Moreover, there is a great variety in the way firms use transfer pricing. Many firms with high R\&D intensities do not even use transfer- or royalty payments for technology. And for firms which do use such payments, there are reasons to believe that they would distort such prices or payments to avoid taxes, or other costs created by government policies.

${ }^{19}$ For a small subsidy it can also be shown from (A1) in the Appendix that market size $s$ only impacts the location choice from the return to $\mathrm{R} \& \mathrm{D} \eta=s \frac{\theta^{2}}{\mu}$. Market size is then controlled for by the $\mathrm{R} \& \mathrm{D}$ intensity of a firm.
} 
sales accounted for by the affiliates. Comparing with theory in Table 3, this negative, significant sign is consistent with the relationship predicted by high transfer costs.

Once more, comparing with the theory in Table 3, we should then expect to find a negative sign on the subsidy variable, $R D S U B$. This is indeed the case in the OLS (i), the panel estimation with firm-specific effects (ii) and the tobit specification (iii). The sign on the 2SLS estimate is also negative, but in contrast to the other specifications, it is insignificant. However, as shown in Table 6, the IV-regression carries less observations, since when using the four-year lag of $R \& D$ as regressor almost eliminates half of sample. As noted above, the reason for this loss of observations is a heavily unbalanced firm panel, as many firms disappear when they are acquired or reorganized over time.

Turning to transport costs, TRANSP has the predicted, positive sign and is significant in all but the IV regression. The plant-scale variable $G S C A L E$ has the predicted negative sign in all specifications. Once more, the effect is statistically significant in all but the IV regression, showing the problem of loss of observations when using lagged variables. The variable $A G E$ has the predicted sign in all specifications and is strongly significant in all but the specification (ii) with firm-specific effects. ${ }^{20}$ Overall, more experience in foreign production increases the share of foreign sales produced by affiliates abroad.

Finally, I did a robustness checking for the effect of observations with very large values of government subsidies. Excluding these observations did not qualitatively change the results. ${ }^{21}$ Reestimating (16) and examining also a firm's location choice in individual countries, also did not qualitatively change results. ${ }^{22}$

In sum, I find no evidence of subsidies leading to a relocation of production abroad. If anything, there is some evidence of the opposite - that, on the margin, increased R\&Dsubsidies give rise to more exports. This is consistent with the theory, given the finding that, on the margin, exports and not foreign production is the preferred choice of R\&D-

\footnotetext{
${ }^{20}$ The firm-specific effects pick up the variation in the $A G E$ variable, rendering this variable insignificant. This may be so because for firms remaining in the sample, age-differences between firms are roughly constant over time.

${ }^{21}$ Large subsidies were recorded in 1965 for group 4 (Machinery n.e.c.; Office, accounting and computing machinery; Instruments Electrical machinery; Electronic equipment).

${ }^{22}$ These regressions investigate the location decision for firm $i$ country $j$ at time $t$. In the present paper, the overall location decision of firm $i$ in time $t$ is examined. Results are available on request.
} 
intensive firms.

\section{Conclusions}

The recent financial crises has led governments to increase its industrial support to hightech industries dominated by MNEs. In the literature on MNEs, high R\&D intensity is often associated with multinational firms; this mirrors the development of firm-specific assets such as technology, which are seen as essential for expanding sales and production into foreign markets. Subsidizing R\&D in such firms, it is not evident that an MNE will expand its home-based production of high-tech goods or services. Indeed, as shown in this paper, when technology transfer costs are low, R\&D-subsidies may instead lead to a relocation of R\&D-intensive production abroad, as subsidies reinforce a two-way relationship between $R \& D$-expenditures and foreign expansion, where the larger scale in foreign production (as trade costs are avoided) facilitate additional R\&D-expenditures. This leaves the effectiveness of government policies aiming at strengthening the technological base of domestic industries in doubt, if arguments in favor of such policies are based on hopes of increasing domestic high-tech production.

Studying historical data on Swedish Multinational firms for a long time period gives no evidence that $R \& D$ subsidies may relocate high-tech production, however. Instead, the data is consistent with R\&D-subsidies tending to lead to increased home based export production. R\&D subsidies do not lead to a relocation since R\&D-intensive firms tend to prefer export production from the home country, where new products and technologies are development. ${ }^{23} \mathrm{R} \& \mathrm{D}$-intensive firms may then gain more by avoiding transfer costs of technology than by avoiding trade costs of physical units, since more complex technologies demand larger resources for technology transfer.

The negative correlation between technology and foreign location of production is in contrast with the common notion in the literature of MNEs being R\&D intensive firms, but confirms the findings in Norbäck (2001), where the same result was found on a more dis-

\footnotetext{
${ }^{23}$ Within Swedish MNEs, the bulk of R\&D takes place at home, although there is an increasing share of foreign $\mathrm{R} \& \mathrm{D}$, which might indicate that $\mathrm{R} \& \mathrm{D}$ for developing new products and technologies is to a larger extent carried out abroad.
} 
aggregated sample. Given the many examples of large MNEs in R\&D-intensive industries, this seems paradoxical, but simply suggests that such firms tend to keep their high-tech activities at home, whereas less R\&D-intensive activities are carried out abroad. ${ }^{24}$

A weakness of the empirical analysis is that, while I do have firm-level data on the location and R\&D choices, I do not have access to data government subsidies at the firmlevel. Such data is to my knowledge not available for the studied time period. I have also abstracted from the effects tax incentives on R\&D and how this may affect the location of production. According to the classification of OECD, governments support to R\&D in Sweden is more directed to giving direct funding than supporting R\&D through tax incentives. ${ }^{25}$ An extension of the analysis incorporating tax incentives would nevertheless give new insights but is subject to future research.

\footnotetext{
${ }^{24}$ It might be argued that there is a sample selection bias present since purely exporting firms are absent in the RIIE sample. However, there also seems to be an export-bias for R\&D-intensive firms in other studies. In Brainard (1997), where trade data from the US Bureau of Census and FDI data from the Bureau of Economic Analysis are combined, it is found that when levels of affiliate production and exports are regressed separately against $R \& D$ intensity; both increase in $R \& D$, but the elasticity of exports is about two and half times larger. While R\&D intensity is not used as a regressor when explaining the variation in the affiliate share of foreign sales, these elasticities implicitly suggest a negative correlation.

${ }^{25}$ See, http://www.oecd.org/dataoecd/12/27/2498389.pdf.
} 


\section{References}

Barba Navaretti, G. and A. Venables. 2004. Multinational firms in the world economy. Princeton University Press.

Blomstrom, M., 2000. Internationalization and Growth: Evidence from Sweden, Swedish Economic Policy Review v7, n1, 185-201.

Brander, J.A., 1995. Strategic trade policy, Grossman and Rogoff (eds.): Handbook of International Economics, Volume 3, Amsterdam: Elsevier.

Brainard, Lael S., 1997. An empirical assessment of the proximity-concentration trade-off between multinational sales and trade. American Economic Review 87, 520-544.

Caves, R.E., 1996. Multinational Enterprise and Economic Analysis. 2nd edition, (Cambridge University Press, Cambridge and New York).

Cheng, L., 1984. International competition in R\&D and technological leadership, Journal of International Economics 17, 15-40.

Dick, A., 1993. Strategic trade policy and welfare: The empirical consequences of crossownership. Journal of International Economics 35, 227-249.

Dunning, J.H., 1977. Trade, location of economic activities and the MNE: A search for an eclectic approach, in P.-O. Hesselborn, B. Ohlin and P.-M. Wijkman, eds., The International Allocation of Economic Activity, (MacMillan, London), 395-418.

Flam, H., 1994, EC members fighting about surplus: VERs, FDI and Japanese cars, Journal of International Economics 36, 117-131.

Haaland, J. and Kind, H., 2008. "R\&D policies, trade and process innovation,"Journal of International Economics 74(1), 170-187.

Horstmann, I. and J.R. Markusen, 1992. Endogenous market structures in international trade (natura facit saltum), Journal of International Economics 32, 109-129.

ITPS, 2007. "Forskning och utvecklingi internationella företag", S2007:006. 
Jakobsson, Ulf, 1999. Storföretagen och den ekomiska tillväxten, in L. Calmfors and M. Persson, eds., Tillväxt och ekonomisk politik, 329-356.

Leahy, D. and P. Neary, 1996. International R\&D rivalry and industrial strategy without government commitment, Review of International Economics 4, 322-338.

Leahy, D. and P. Neary, 2009. Multilateral Subsidy Games, forthcoming Economic Theory.

Markusen, J.R., 1995. The boundaries of multinational enterprises and the theory of international trade, Journal of Economic Perspectives 9, 169-189.

Markusen, J.R., (2002), Multinational Firms and the Theory of International Trade, The MIT Press, Cambridge.

Norbäck, P-J, 2001. Multinational Firms, Technology and Location, Journal of International Economics 54, 449-469.

OECD, 1996. "Public support to Industry, 1989-1993. Report by the Industry Committee Council at Ministerial level", [OECD/GD(96)82], Paris.

OECD, 1997. Economic Outlook No 61: Annual Data (OECD Publishers).

Ravenscraft, D. and F. Scherer, 1982. The lag structure of returns to research and development, Applied Economics 14, 603-620.

Sanna-Randaccio, F. 2002. The impact of Foreign Direct Investment on the Home and Host Countries with Endogenous R\&D, Review of International Economics, 10(2), 278-298.

SCB, Industristatistiken. (Statistiska Central Byrån).

Swedenborg, B., 1982. Swedish Industry Abroad. An Analysis of Driving-Forces and Effects, (IUI, Stockholm).

Teece, D.J., 1977. Technology transfer by multinational firms: The resource cost of transferring technological know-how, Economic Journal 87, 242-61. 
World Bank, 1997. World Development Indicators (World Bank). 


\section{Appendix:}

First, the statements in Lemmas 1 and 2 are proved, then Table 3 is derived. A simulation of the model is also provided. Finally, second-order conditions are shown.

\subsection{Proof of Lemmas 1 and 2}

In Table 7, I provide most expressions needed for this appendix. These can be derived noting that $\Pi_{h}$ from Table 2 can be written as follows:

$$
\Pi_{E}=\frac{1}{2 s} \frac{\left(s(A-t)+\sigma \frac{\eta}{\theta}\right)^{2}}{2-\eta}+\frac{\sigma^{2}}{2 \gamma}, \quad \Pi_{A}=\frac{1}{2 s} \frac{\left(s A+\sigma \frac{\eta}{\tau \theta}\right)^{2}}{2-\frac{\eta}{\tau}}-G+\frac{\sigma^{2}}{2 \gamma \tau} .
$$

The first entries in the first row in Table 7 proves Lemma 1. To prove Lemma 2, define the difference in variable profits as $\triangle \Pi=\Pi_{E}-\Pi_{A}$. It is easily seen that $\tau=\infty$ (infinite transfer costs) implies $\frac{\partial \triangle \Pi}{\partial \eta}>0$, whereas $\tau=1$ (no transfer costs) implies $\frac{\partial \Delta \Pi}{\partial \eta}<0$. It follows that $\frac{\partial \triangle \Pi}{\partial \eta}$ must be monotonically increasing in $\tau$. Then, define $\tau^{*}$ such that $\frac{\partial \triangle \Pi\left(\left(\tau^{*}, \mathbf{z}\right)\right.}{\partial \eta}=0$. Hence, if there is a $\eta=\eta^{*}$ such that $\triangle \Pi\left(\eta^{*}, \mathbf{z}\right)=0 \Leftrightarrow \Pi_{E}\left(\eta^{*}, \mathbf{z}\right)=\Pi_{A}\left(\eta^{*}, \mathbf{z}\right)$, where $\mathbf{z}$ is the vector of exogenous variables, it follows that $\Pi_{E}<\Pi_{A}$ for $\eta>\eta^{*}$ and $\tau<\tau^{*}$, whereas $\Pi_{E}>\Pi_{A}$ for $\eta>\eta^{*}$ and $\tau>\tau^{*}$.

\subsection{Proof of Proposition 3}

I show only the proof for a small subsidy. Below, I provide a simulation illustrating that results also extend beyond infinitesemal subsidies.

Using the equality $\Pi_{E}\left(\eta^{*}, \mathbf{z}\right)=\Pi_{A}\left(\eta^{*}, \mathbf{z}\right)$, implicit differentiation yields:

$$
\frac{d \eta^{*}}{d z}=-\frac{\frac{\partial\left(\Pi_{E}-\Pi_{A}\right)}{\partial z}}{\frac{\partial\left(\Pi_{E}-\Pi_{A}\right)}{\partial \eta}}=-\frac{\frac{\partial \Delta \Pi}{\partial z}}{\frac{\partial \Delta \Pi}{\partial \eta}},
$$

where (A2) is used to determine the signs in Table 3. Inserting the appropriate expressions from Table 7 in (A2) yields these signs. Inspecting table 7, it can be shown that there exists a $\hat{\tau}$, such that $\tau>\hat{\tau}$ implies $\frac{\partial\left(\Pi_{E}-\Pi_{A}\right)}{\partial \sigma}>0$, a $\tilde{\tau}$ such that $\tau>\tilde{\tau}$ implies $\frac{\partial\left(\Pi_{E}-\Pi_{A}\right)}{\partial \eta}>0$ and that $\hat{\tau}>\tilde{\tau}>0$ holds. Setting $\tau^{*}=\hat{\tau}$ completes the proof of Proposition 3 . 


\subsubsection{A simulation with non-infinitesemal R\&D-subsidies}

Here, I present a simulation showing that the results also extend into subsidies which are not infinitesimal. Figure 1 shows how large the trade cost must be for the firm to be indifferent between affiliate- and export production. More formally, I define this critical trade cost, $t^{*}$, where $\Pi_{E}\left(t^{*}, \mathbf{z}\right)=\Pi_{A}\left(t^{*}, \mathbf{z}\right)$. In Figure $1, t^{*}$, is plotted against the transfer cost, $\tau$, and the return to $\mathrm{R} \& \mathrm{D}, \eta$. Other parameter values are $A=s=5, \sigma=0.5$, $\theta=0.2$ and $G=1$. Figure 1 is easily interpreted: If trade costs are above the surface $t^{*}$, "tariff-jumping" occurs and the firm chooses FDI. Conversely, if trade cost are below $t^{*}$, export production takes place. Note that when transfer costs $\tau$ are high (low) and the return to R\&D $\eta$ is high, exports (FDI) are chosen, as predicted by the theory in section 2.

In figure 2, I make the following experiment. Suppose that the R\&D subsidy is originally set at $\sigma=0.5$, generating the critical trade cost $\left.t^{*}(\tau, \eta)\right|_{\sigma=0.5}$ shown in Figure 1, where once more $t^{*}$ is level of the trade cost such that the firm is indifferent between the two location strategies. Figure 2 then shows the effect on the location decision of an increase in the R\&D subsidy from $\sigma=0.5$ to $\sigma=3$. Calculating $\left.t^{*}(\tau, \eta)\right|_{\sigma=3}$, it follows that the firm chooses affiliate production whenever $\left.t^{*}(\tau, \eta)\right|_{\sigma=3}<\left.t^{*}(\tau, \eta)\right|_{\sigma=0.5}$ and export production, whenever the opposite holds. As predicted from the theory, it can be seen that when transfer costs are absent or low, FDI is chosen. However, once the return to $\mathrm{R} \& \mathrm{D} \eta$ is sufficiently increased for positive transfer costs, exports are preferred. This is also the case for higher transfer costs, irrespective of the return to R\&D.

\subsection{Appendix: Second-order conditions}

In this appendix, we check the firm's second-order conditions for the maximization of $\Pi_{h}$. For having a well-posed maximization problem, the Hessian, defined in (A3), must be negative definite:

$$
Q_{h}=\left[\begin{array}{ll}
\Pi_{h, q_{h}, q_{h}} & \Pi_{h, q_{h}, x_{h}} \\
\Pi_{h, x_{h}, q_{h}} & \Pi_{h, x_{h}, x_{h}}
\end{array}\right],
$$

where, for example, $\Pi_{h, q_{h}, x_{h}}=\frac{\partial^{2} \Pi_{h}}{\partial q_{h} \partial x_{h}}$. This, in turn, requires that $\left|Q_{h}\right|>0, \Pi_{h, q_{h}, q_{h}}<0$ and $\Pi_{h, x_{h}, x_{h}}<0$. I can show that this will hold if $\frac{\eta}{\tau}<2$, since: 


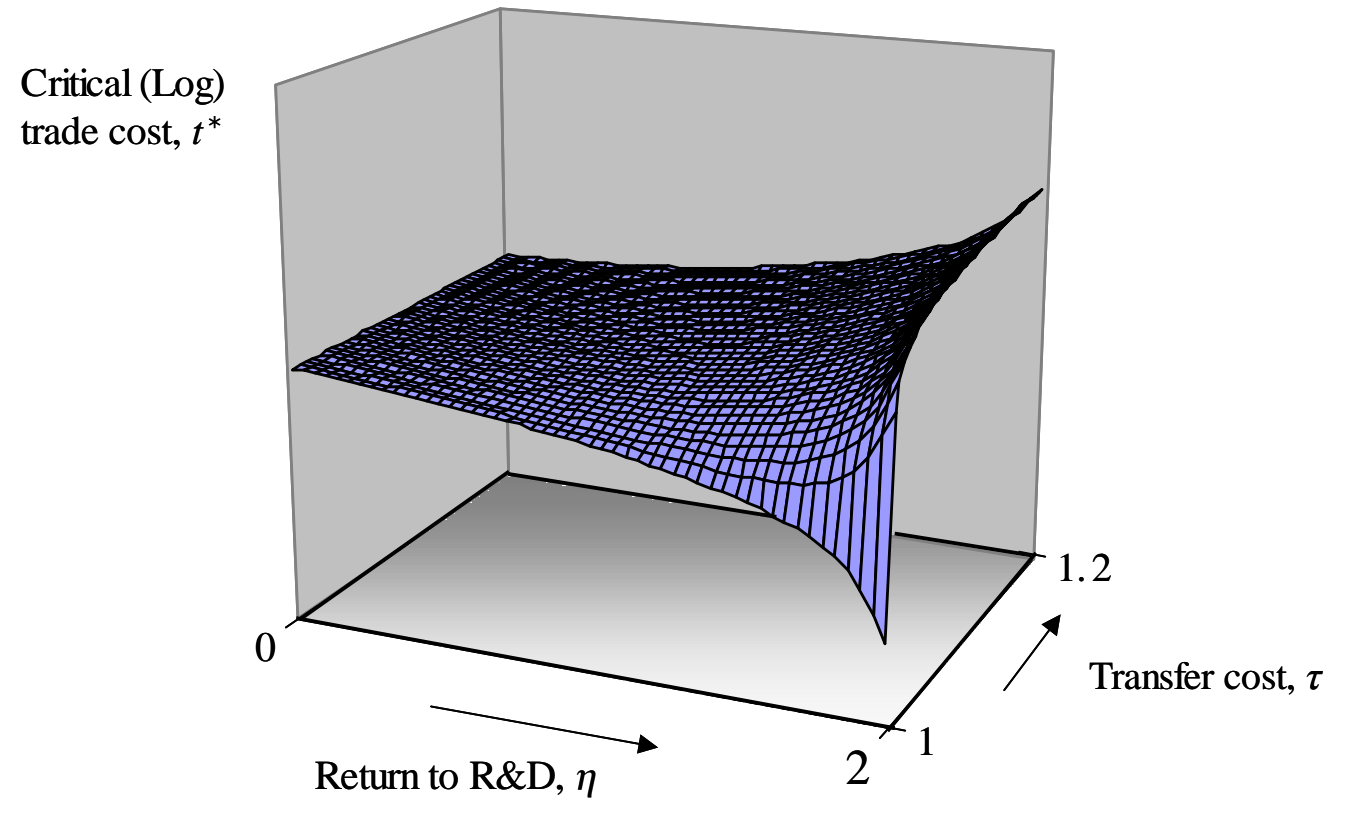

Figure 1: Trade costs $t^{*}$ at which the firm is indifferent between affiliate- and export production. $A=s=5, \sigma=0.5, \theta=0.2$ and $G=1$

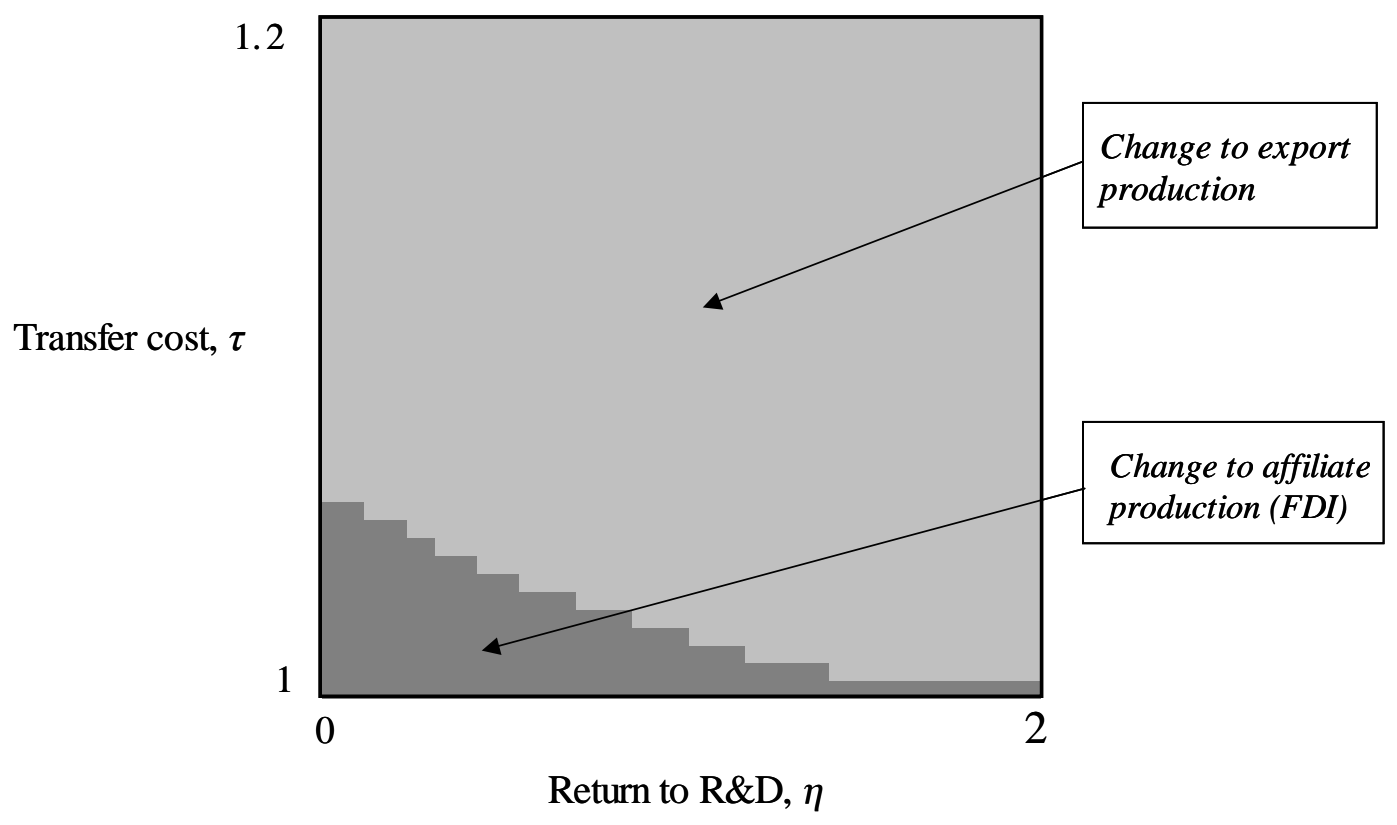

Figure 2: The effect on the firm's location decision of an increase in the subsidy from $\sigma=0.5$ to $\sigma=3$. Other paramers at $A=s=5, \theta=0.2$ and $G=1$. 


$$
\begin{aligned}
& \left|Q_{E}\right|=\frac{\gamma}{s}(2-\eta), \quad \Pi_{E, q_{E}, q_{E}}=-\frac{2}{s}<0, \quad \Pi_{E, x_{E}, x_{E}}=-\gamma<0 \\
& \left|Q_{A}\right|=\frac{\gamma}{s}(2 \tau-\eta), \quad \Pi_{A, q_{A}, q_{A}}=-\frac{2}{s}<0, \quad \Pi_{A, x_{A}, x_{A}}=-\frac{\gamma}{\tau}<0 .
\end{aligned}
$$


Table 4: Description of variables.

\begin{tabular}{|c|c|c|c|}
\hline Variable & Proxy & $\begin{array}{l}\text { Expected } \\
\text { sign }\end{array}$ & $\begin{array}{l}\text { Description and } \\
\text { source }\end{array}$ \\
\hline$\eta$ & $R D I N T$ & (see, Table 3) & $\begin{array}{l}\text { share of a firm's total R\&D expenditures in its } \\
\text { total sales (RIIE) }\end{array}$ \\
\hline$\sigma$ & $R D S U B$ & (see, Table 3) & $\begin{array}{l}\text { share of total R\&D expenditures at the Swedish } \\
\text { two-digit industry level financed by the } \\
\text { government. ((OECD, SCB) }\end{array}$ \\
\hline$t$ & $T R A N S P$ & + & $\begin{array}{l}\text { share of transport costs in total variable costs } \\
\text { at the three- or four-digit level in the Swedish } \\
\text { industry to which the firm belongs (SCB). }\end{array}$ \\
\hline$\tau$ & $A G E$ & + & $\begin{array}{l}\text { weighted average of the mean age of the firm's } \\
\text { affiliates in the respective countries where a } \\
\text { firm has affiliates (RIIE). }\end{array}$ \\
\hline$G$ & $G S C A L E$ & - & $\begin{array}{l}\text { average size of plants with more than one hundred } \\
\text { employees at the three- or four-digit level Swedish } \\
\text { industry, to which the firm belongs. (SCB). }\end{array}$ \\
\hline
\end{tabular}

Note: The industry groups for which subsidies data are calculated are: (1) Food; beverages and tobacco; (2) Coke; petrolium; nuclear fuel; chemicals; rubber; plastics; (3) Basic metals; fabricated metal products; (4) Machinery n.e.c.; office, accounting and computing machinery; instruments electrical machinery; electronic equipment; (5) Motor vehicles; other transport equipment; (6) Pulp, paper and paper products and (8) Textiles, apparel, furniture and leather; Wood and cork (not furniture); furniture; non-metallic mineral products 
Table 5: Summary statistics of the data.

\begin{tabular}{lccccc}
\hline Variable: & Obs & Mean & Std. Dev. & Min & Max \\
\hline \hline AFSHARE & 632 & 0.54 & 0.32 & 0 & 1 \\
RDINT & 632 & 0.02 & 0.03 & 0 & 0.19 \\
RDSUB & 632 & 0.07 & 0.09 & 0 & 0.54 \\
TRANSP & 632 & 0.03 & 0.02 & 0.001 & 0.15 \\
AGE & 632 & 9 & 10 & 0 & 74 \\
GSCALE & 632 & 358 & 208 & 161 & 1867 \\
\hline
\end{tabular}

Note : AGE is 0 if affiliates "are born" in the same year as the survey takes place 
Table 6: Estimation results. Dependent variable: the affiliates share of foreign sales, AFSH ARE.

\begin{tabular}{|c|c|c|c|c|c|}
\hline \multirow[t]{2}{*}{ Specification: } & (i): & (ii) & (iii) & (iv) & \multirow[b]{2}{*}{ Exp. sign } \\
\hline & OLS & $\mathrm{FE}$ & Tobit & IV & \\
\hline \multirow[t]{2}{*}{ RDINT } & $-1.45^{* * *}$ & $-3.33^{* * *}$ & $-1.59^{* * *}$ & $-1.49^{* *}$ & \\
\hline & $(-3.17)$ & $(-3.65)$ & $(-3.08)$ & $(-2.21)$ & \\
\hline \multirow[t]{2}{*}{ RDSUB } & $-0.38^{* *}$ & $-0.25^{*}$ & $-0.50 * *$ & -0.03 & \\
\hline & $(-2.34)$ & $(-1.69)$ & $(-2.71)$ & $(-0.08)$ & \\
\hline \multirow[t]{2}{*}{ TRANSP } & $1.91^{* *}$ & $2.45^{* *}$ & $2.04^{* *}$ & 1.67 & + \\
\hline & $(2.40)$ & $(2.13)$ & $(2.38)$ & $(1.09)$ & \\
\hline \multirow[t]{2}{*}{ GSCALE } & $-0.0002^{*}$ & -0.0001 & $-0.0002^{* *}$ & -0.0002 & - \\
\hline & $(-1.81)$ & $(-1.44)$ & $(-2.09)$ & $(-1.30)$ & \\
\hline \multirow[t]{2}{*}{ AGE } & $0.005^{* * *}$ & 0.001 & $0.006^{* * *}$ & $0.004^{* *}$ & + \\
\hline & $(4.04)$ & $(0.49)$ & $(4.22)$ & $(2.52)^{*}$ & \\
\hline Adj $R^{2}$ & 16.8 & 47.1 & & 11.8 & \\
\hline $\mathrm{F}$ & $7.08^{* * *}$ & $4.26^{* * *}$ & & $108.4^{* * *}$ & \\
\hline LR & & & $129.95^{* * *}$ & & \\
\hline Obs & 632 & 632 & 632 & 347 & \\
\hline Left/Unrestr/Right & & & $38 / 549 / 45$ & & \\
\hline Fixed effects & $\begin{array}{l}\text { Industry, } \\
\text { year }\end{array}$ & $\begin{array}{l}\text { Firm, } \\
\text { year }\end{array}$ & $\begin{array}{l}\text { Industry, } \\
\text { year }\end{array}$ & $\begin{array}{l}\text { Industry, } \\
\text { year }\end{array}$ & \\
\hline No. of groups & & 291 & & & \\
\hline F (firm) & & $2.54^{* * * *}$ & & & \\
\hline
\end{tabular}

Note: Remarks: * **, *** indicate significance at the 1 percent, 5 percent and 10 percent level, respectively. 
Table 7: Comparative statics.

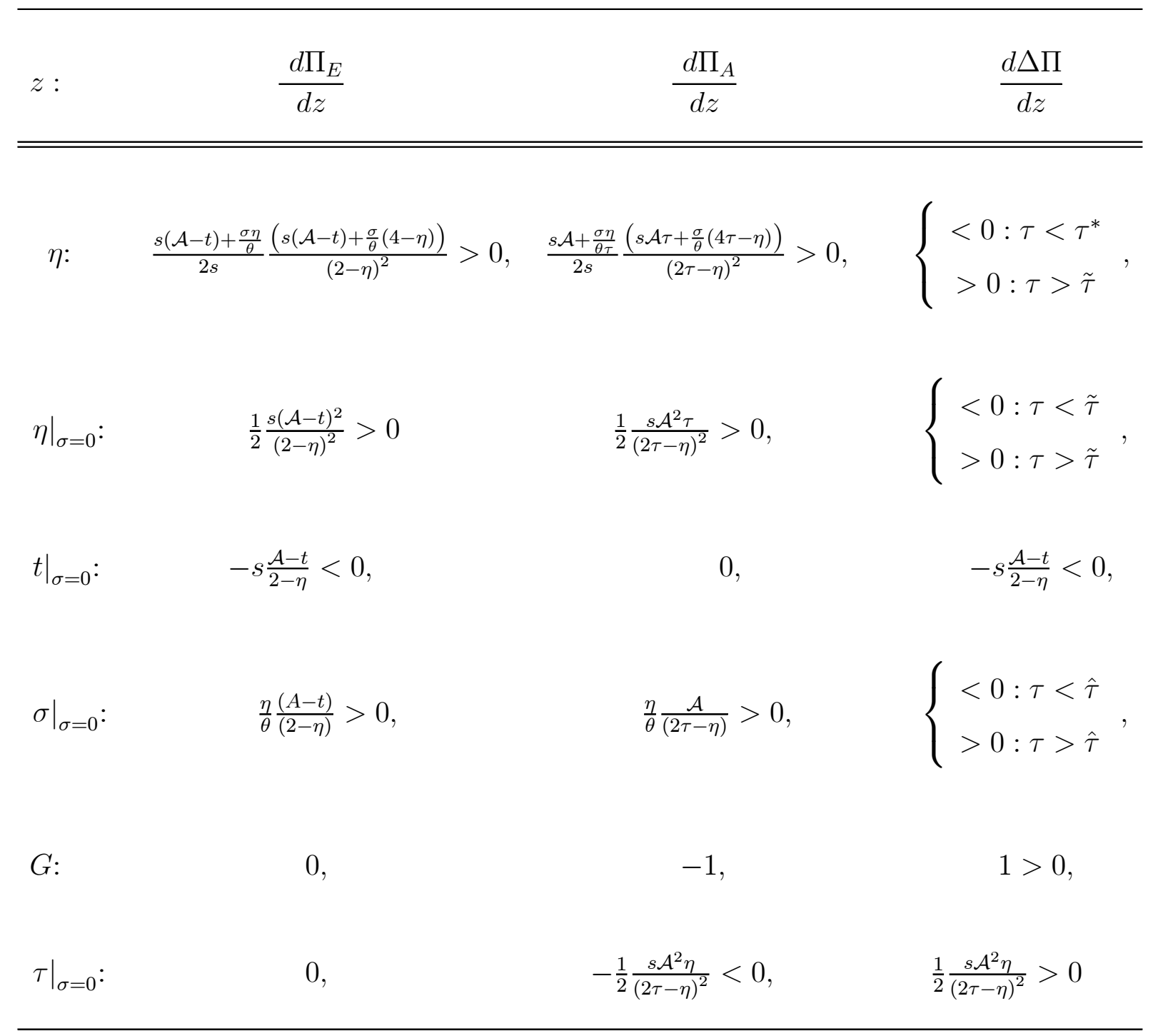

